\title{
Comparative in Vitro Evaluation of Different Brands of Metformin Hydrochloride Film Coated Tablets Marketed in Addis Ababa, Ethiopia
}

\author{
Kassa Abate, Abrham Temesgen, Muluken Nigatu*
}

Department of Pharmaceutics and Social Pharmacy, School of Pharmacy, College of Health Sciences, Addis Ababa University, P.O. Box 1176, Addis Ababa, Ethiopia.

\begin{abstract}
A B S T R A C T
Metformin hydrochloride is a biguanide class of drug widely used to treat Type 2 diabetes mellitus. Its oral bioavailability is about 50 to $60 \%$ with a half-life of about $3 \mathrm{~h}$. This study focused on evaluation and comparison of the physicochemical properties of different brands of metformin hydrochloride $(500 \mathrm{mg})$ film coated tablets available in drug retail outlets in Addis Ababa, Ethiopia. Some different in vitro tests including hardness, weight variation, disintegration time, dissolution study, and assay were conducted as per United States Pharmacopeia. To compare dissolution profiles of the generic products against the innovator product (product A), a model independent method, similarity factor (f2), was also used. Weight variation result showed that all brands fall within the $5 \%$ limit from the average which is acceptable. Disintegration time of less than 15 minutes was observed for all brands. The in vitro drug release study results for the products ranged between 82 and $93 \%$ release within 30 minutes which is above $80 \%$ limit as per the United States Pharmacopeia requirement. The f2 values for generic products ranged from 53 to $75 \%$. Furthermore, assay value of the studied brands varied from 95.60 to $104.37 \%$ which was within standard limit (95-105\%). It can be concluded that all brands of metformin hydrochloride tablets met pharmacopoeial specification for the tested parameters of physicochemical properties like weight variation, hardness of tablets, disintegration time, drug release study and assay.
\end{abstract}

Key words: Metformin hydrochloride, drug release, physicochemical properties, diabetes, tablets.

A R T I C L E I N F 0: Received 08 April 2020; Review Completed 28 May 2020; Accepted 06 June 2020; Available online 15 June. 2020

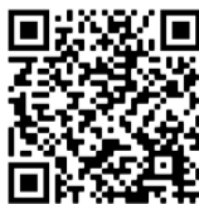

Cite this article as:

Abate K, Temesgen A, Nigatu M, Comparative In Vitro Evaluation Of Different Brands Of Metformin Hydrochloride Film Coated Tablets Marketed In Addis Ababa, Ethiopia, Asian Journal of Pharmaceutical Research and Development.

2020; 8(3):44-50 DOI: http://dx.doi.org/10.22270/ajprd.v8i3.746

*Address for Correspondence:

Muluken Nigatu, Department of Pharmaceutics and Social Pharmacy, School of Pharmacy, College of Health Sciences, Addis Ababa University, P.O. Box 1176, Addis Ababa, Ethiopia.

\section{INTRODUCTION}

$\mathrm{D}$ iabetes is one of the major causes of death and disability in the world. It is estimated that 366 million people will be diagnosed for diabetes worldwide in 2030. Type 2 diabetes mellitus is a rapidly growing health concern in both developed and developing nations and it accounts for about 90 to $95 \%$ of all diagnosed cases of diabetes in adults, ${ }^{1,2}$. Among the treatment drugs options, Metformin hydrochloride is the most widely used oral medication to treat type 2 diabetes worldwide ${ }^{2}$.

Metformin hydrochloride, chemically N,Ndimethylimidodicarbionimidic diamide hydrochloride $(1,1-$ diamethylbiguanide hydrochloride), belongs to the 'biguanide' class as shown in Figure 1,3.<smiles>CN(C)C(=N)NC(=N)N</smiles>

Figure 1: Chemical structure of metformin hydrochloride

After oral administration, metformin is mainly absorbed from the upper small intestine, and it undergoes limited systemic absorption (absolute bioavailability is about 50 to $60 \%$ ) with a half-life of about $3 \mathrm{~h}$. Therefore, repeated administration of the conventional metformin hydrochloride tablets is needed for effective treatment ${ }^{4-6}$. 
Metformin hydrochloride is highly soluble and has low permeability. It is therefore, according to Biopharmaceutical Classification System (BCS), a class III drug and is eligible for bio-waiver based on the World Health Organization (WHO) criteria ${ }^{7}$.

Following the expiry of the innovator drug patent (Glucophage®) in 2001, many generic pharmaceutical companies have manufactured oral metformin hydrochloride tablets and joined the market. ${ }^{2,5}$ Such introduction of generic drug products from multiple sources into the markets improved availability and access to this life-saving drug especially in developing countries ${ }^{8}$. Moreover, these generic products are marketed with lower price and associated with public health cost reduction ${ }^{9,10}$. Despite these benefits, generic products are also related with variety of problems which might place the customers' health in to risk. The interchangeability of generic drugs with the originator might still be questionable.

Quality is one of the most important criteria in ensuring optimal treatment from medicines and are currently receiving increased attention in generic manufacturing ${ }^{11}$.

There are few pharmaceutical industries in Ethiopia and the country is mainly dependent on imported products. Different local and multinational brands of metformin hydrochloride tablets are available in the country. There should be a means to ensure that generic pharmaceutical drug products are therapeutically equivalent and interchangeable with their associated innovator's product as variable clinical responses have been reported from similar drug products supplied by different manufacturers ${ }^{12,13}$.

Some studies in different countries compared the performance of innovator and generic products of metformin hydrochloride tablets ${ }^{8,13-17}$. The results showed that there are some generic products which didn't satisfy the pharmacopoeial specifications for some quality parameters.

Medicine quality problems could be fatal and have also been associated with severe economic consequences ${ }^{11}$. According to estimation of WHO, about $10 \%$ medical products circulating in low- and middle-income countries is either substandard or falsified ${ }^{18}$. This figure indicates the urgent need to address this problem.

The generic pharmaceutical drug products have to conform to the same standards of quality, efficacy and safety required of innovator drug products ${ }^{19}$. In Ethiopian market, there are several brands of metformin hydrochloride tablets which require the need to evaluate their quality.

While bioequivalence testing of generic tablet products against an innovator product is required by regulatory bodies during a process of market authorization, the relative performance of the various generic formulations is not routinely tested ${ }^{20}$.

In the current study, in vitro equivalency evaluation of metformin hydrochloride $500 \mathrm{mg}$ film coated tablets were carried out. Seven different brands of metformin hydrochloride tablets were tested and compared for different physicochemical quality parameters including hardness, weight variation, disintegration, dissolution and assay.

\section{EXPERIMENTAL}

\section{Materials}

Metformin hydrochloride reference standard was kindly supplied by the Ethiopian Food and Drug Authority (EFDA). The innovator product (code A) and other six different brands of metformin hydrochloride tablets (Table 1) with label strength of 500mg were purchased from different retail outlets in Addis Ababa, Ethiopia. All are immediate release film coated tablets. Potassium phosphate monobasic (FARMITALIA CAROERBA, Italy), Sodium hydroxide (BDH limited, Poole, England) and distilled water were used for the study. All chemicals used were analytical grade and used as received.

Table 1: Some details of metformin hydrochloride tablet products evaluated in the study

\begin{tabular}{|l|l|l|l|}
\hline $\begin{array}{l}\text { Product } \\
\text { Code }\end{array}$ & $\begin{array}{l}\text { Country of } \\
\text { origin }\end{array}$ & Batch number & $\begin{array}{l}\text { Expiry date } \\
(\mathbf{m m} / \mathbf{y y y y})\end{array}$ \\
\hline A & France & F0579B & $05 / 2023$ \\
\hline B & Cyprus & A1H115 & $08 / 2022$ \\
\hline C & Cyprus & 77222 & $06 / 2023$ \\
\hline D & Poland & JC2413 & $06 / 2021$ \\
\hline E & Germany & 9 NP & $09 / 2023$ \\
\hline F & Ethiopia & D18070T212 & $11 / 2021$ \\
\hline G & Ethiopia & 26235 & $06 / 2020$ \\
\hline
\end{tabular}

\section{Methods}

\section{Thickness measurement}

Thickness was measured using sliding caliper scale (Nippon Sokutei, Japan) after randomly taking ten tablets from each brand. Results were expressed as a mean and standard deviation.

\section{Hardness}

Tablets' crushing strengths were determined using hardness tester (Schleuniger, 2E/205, Switzerland). For measurement of hardness, ten tablets from the sample of each brand were selected randomly and force was exerted by placing each tablet between two anvils. The force needed to break the tablet was recorded as a crushing strength of that tablet. Results were expressed as a mean and standard deviation.

\section{Weight variation test}

The test was performed as per the United States Pharmacopeia (USP) ${ }^{21}$ procedure. Twenty tablets were randomly selected from each brand product, then the tablets were individually weighed using electronic balance (AAA 250L, Wagtech international Ltd, England), and the average weights as well as the percentage (\%) deviation of the individual tablets from the mean were determined.

The following equation was used to determine the percent weight variation of tablets:

$$
\text { Percent weight variation }=\frac{\mid \text { Individual weight }- \text { Average weight } \mid}{\text { Average weight }} \text { X100 }
$$

\section{Disintegration Test}

Disintegration test was carried out by placing a randomly selected six tablets from each brand in a disintegration tester (CALEVA, G.B. Caleva Ltd., UK). The disintegration apparatus was filled with distilled water and 
maintained at $37 \pm 2{ }^{\circ} \mathrm{C}$, as a test fluid. While the apparatus is running, the time required for all six tablets of a given brand to break up and the primary particles to completely pass through the mesh of the disintegration basket was recorded and the mean disintegration time was determined.

\section{Construction of calibration curve for metformin hydrochloride}

Metformin hydrochloride reference standard solution was prepared in different concentrations $(3,4,5,6$, and 7 $\mu \mathrm{g} / \mathrm{ml})$ using phosphate buffer $(\mathrm{pH}=6.8)$ medium. Their absorbances were measured at $\lambda_{\max }$ of $233 \mathrm{~nm}$ using a UVVisible spectrophotometer (Double beam UV-Visible Spectrophotometer, T92+, PG instrument limited).

\section{In vitro drug release study}

The in-vitro dissolution study of metformin hydrochloride tablets was carried out using USP type II dissolution apparatus (ERWEKA, DT600, Germany) at rotation speed of $50 \mathrm{rpm}$. The water bath was filled up to the required level and the dissolution vessels were filled with $1000 \mathrm{ml}$ phosphate buffer $(\mathrm{pH}=6.8)$ as dissolution medium. The temperature of the medium was maintained at $37 \pm 0.5^{\circ} \mathrm{C}$.

Six tablets were randomly selected from each brand and placed in separate dissolution vessels. The dissolution was carried out for 45 minutes. At the specified intervals $(5,10$, $15,20,30$ and 45 minutes), $10 \mathrm{ml}$ dissolution samples were withdrawn and replaced with an equal amount of blank dissolution medium maintained at same temperature. The withdrawn samples were filtered and their absorbance values were determined at $233 \mathrm{~nm}$ using UV-Visible spectrophotometer (Double beam UV-Visible Spectrophotometer, T92+, PG instrument limited) by making appropriate dilution. The amount of metformin hydrochloride released was then calculated based on the equation obtained from the calibration curve.

\section{Similarity (f2) factor}

The similarity factor (f2) is a logarithmic reciprocal square root transformation of the sum of squared error and is a measurement of the similarity in the $\%$ dissolution between two curves. The following equation was used to calculate the similarity factor (f2) form result of in vitro drug release.

$$
\left.\mathrm{f} 2=50 \log \left(\left(1+1 / n \sum_{i=1}^{n}(\mathrm{Rt}-\mathrm{Tt})^{2}\right)\right)^{-0.5} \mathrm{x} 100\right)
$$

Where $\mathrm{Rt}$ and $\mathrm{Tt}$ are the cumulative percentage of dissolved drug for the reference and test formulation at time $\mathrm{t}$, respectively, and $\mathrm{n}$ is the number of time points.

\section{Assay of metformin hydrochloride tablets}

The test for assay was done as per $\mathrm{USP}^{21}$ to find out the actual amount of active ingredient present in the tablet of each brand compared with the labeled amount. First a 10 $\mu \mathrm{g} / \mathrm{ml}$ concentration of metformin hydrochloride reference standard in water was prepared as a standard solution from the prepared stock solution $(500 \mu \mathrm{g} / \mathrm{ml})$.

Then sample solution was prepared by taking samples from each brand. Twenty tablets of each brand of metformin hydrochloride tablet were weighed and finely powdered. A quantity of the powder equivalent to $100 \mathrm{mg}$ of metformin hydrochloride was weighed and transferred into 100-ml volumetric flask and dissolved in about $70 \mathrm{~mL}$ of water.
After mechanically shaken (Heidolph Unimax 1010, Germany) for 15 minutes at $200 \mathrm{rpm}$, it was diluted with water to volume and filtered using Whatman No.1 filter paper. Ten $\mathrm{ml}$ of the filtrate was diluted with water to 100 $\mathrm{mL}$ after discarding the first $20 \mathrm{ml}$ of the filtrate. Finally, $10 \mathrm{ml}$ of the resulting solution was further diluted with water to $100 \mathrm{ml}$ to get the nominal concentration of 10 $\mu \mathrm{g} / \mathrm{ml}$ solution.

The absorbances of the standard and sample solutions were determined using UV/Visible spectrophotometer (Double beam UV-Visible Spectrophotometer, T92+, PG instrument limited) at $232 \mathrm{~nm}$ by taking water as a blank. The percentage of the labeled amount of metformin hydrochloride in each brand was calculated using the following equation:

$$
\text { Assay }(\%)=\left(\frac{A_{u}}{A_{s}}\right) \times\left(\frac{C_{s}}{C_{u}}\right) \times 100
$$

Where,

$\mathbf{A}_{\mathbf{u}}:$ Absorbance of the sample solution

$\mathbf{A}_{\mathrm{s}}$ : Absorbance of the standard solution

$\mathbf{C}_{\mathbf{s}}$ : Concentration of metformin hydrochloride in the standard solution

$\mathbf{C}_{\mathbf{u}}$ : Concentration ofmetformin hydrochloride in the sample solution

\section{Statistical analysis}

All the results were statistically analyzed using Origin 7 Software (OriginLab Corporation, MA, and USA). All the data measured and reported are averages of a minimum of triplicate measurements and the values are expressed as mean \pm standard deviation.

\section{RESULTS AND DISCUSSION}

Circulation of poor quality antidiabetic pharmaceutical products in the market compromises the therapeutic outcome of medication for diabetes. Weak control of such products by regulatory bodies limit investment of major pharmaceutical companies into medicine research and development. Moreover, from healthcare practitioners' point of view, there might be a concern of selection of one product among different available generic drug products in a market ${ }^{8}$.

Therefore, it is recommended to investigate the quality of generic products and evaluate their potential substitution with the innovator product. All metformin hydrochloride tablets investigated in the study were found within their shelf lives. Five of the seven products were imported from different countries from which product A was the innovator one.

\section{Thickness, Hardness and Disintegration time}

Some of metformin hydrochloride tablets' physical characteristics are indicated in Table 2. The thickness measurement results showed that values ranged from 5.16 to $6.35 \mathrm{~mm}$ in which product $\mathrm{A}$ and $\mathrm{B}$ measured the minimum and maximum average thickness among all brands. 
Table 2: Some physical characteristics of metformin hydrochloride tablets included in the study

\begin{tabular}{|l|l|l|l|}
\hline Brand Products & Mean Thickness $(\mathbf{m m}) \pm$ SD & Mean Crushing strength $(\mathbf{N}) \pm$ SD & Disintegration time (min) \pm SD \\
\hline A & $5.16 \pm 0.03$ & $103.8 \pm 10.05$ & $10.95 \pm 0.38$ \\
\hline B & $6.35 \pm 0.04$ & $206.3 \pm 9.46$ & $7.75 \pm 0.54$ \\
\hline C & $5.78 \pm 0.03$ & $209.1 \pm 10.54$ & $8.08 \pm 0.44$ \\
\hline D & $5.74 \pm 0.02$ & $186.1 \pm 9.48$ & $8.45 \pm 0.69$ \\
\hline E & $6.03 \pm 0.04$ & $128.7 \pm 9.33$ & $13.83 \pm 1.20$ \\
\hline F & $5.22 \pm 0.06$ & $118.1 \pm 9.80$ & $2.20 \pm 0.24$ \\
\hline G & $5.47 \pm 0.04$ & $156.6 \pm 17.54$ & $10: 20 \pm 0.78$ \\
\hline
\end{tabular}

Abbreviations: N, Newton; SD, Standard Deviation

Thickness uniformity is one of the requirements for tablets as there might be effect on their acceptance by consumers and proper packaging of the products. USP $^{21}$ stated that tablets thickness for a batch should be found within a $\pm 5 \%$ variation from the required thickness. The study revealed the closeness of tablets' physical thickness as the maximum standard deviation was found to be 0.06. During manufacturing of tablets, thickness of individual tablets depends on factors like fill weight and pressure applied for tablet compression.

Hardness of a tablet is an important parameter for providing optimum effect in the body. If the tablet is very hard it will not disintegrate readily and may lead to failure to meet the dissolution specification. If the tablet is too soft, it will create difficulties during handling, packaging, coating, transportation and dispensing ${ }^{22}$. From Table 2, product $\mathrm{C}$ had the highest crushing strength of all brands with hardness of $209 \mathrm{~N}$ which may be due to the nature and quantity of additives used or the compression force exerted in the manufacturing procedures. Product $\mathrm{A}$ had the minimum hardness value $(104 \mathrm{~N})$. All the brands satisfied the minimum requirement (i.e. $40 \mathrm{~N}$ ) of the non-official hardness test ${ }^{23}$. Such unusual higher values of hardness possessed by the products might be for the purpose of withstanding the mechanical shock during packaging, transportation and handling. This could result from the production process and the nature of ingredients incorporated in the tablets. But, their impact on tablets' disintegration and dissolution should get a due attention as well.

Disintegration test is done to note the time a given tablet takes to break down in to the small particles and it is an initial step before tablet's dissolution ${ }^{24}$. From Table 2, it is also clearly seen that the disintegration time of the studied brands ranged from 2.2 to 13.83 minutes. All brand

Table 3: Weight variation results of different brands of metformin hydrochloride tablets

\begin{tabular}{|l|l|l|l|l|}
\hline Product Code & Mean weight $(\mathbf{m g}) \mathbf{+ S D}$ & $\begin{array}{l}\text { Minimum \% } \\
\text { weight deviation }\end{array}$ & $\begin{array}{l}\text { Maximum \% weight } \\
\text { deviation }\end{array}$ & Number of tablets out of specification \\
\hline A & $532.08+3.74$ & 0.04 & 1.38 & None \\
\hline B & $675.33+5.88$ & 0.05 & 1.96 & None \\
\hline C & $660.48+3.58$ & 0.04 & 1.32 & None \\
\hline D & $524.68+4.69$ & 0.15 & 2.08 & None \\
\hline E & $656.88+5.07$ & 0.01 & 1.6 & None \\
\hline F & $658.04+6.39$ & 0.05 & 2.27 & None \\
\hline G & $664.42+12.33$ & 0.03 & 5.99 & 1 \\
\hline
\end{tabular}

\section{In vitro drug release}

Calibration curve was plotted (Figure 2) using values of absorbance against the corresponding concentrations. The products showed average disintegration time less than 15 minutes which is according to the $\mathrm{USP}^{21}$ specification for immediate release film coated tablets (less than 30 minutes). Brand $\mathrm{F}$ showed the fastest disintegration time (2.2 $\mathrm{min}$ ) which might contribute for the rapid release of the contents during tablet dissolution process. Incorporation of super disintegrants might facilitate such rapid breaking of tablets into primary particles for brand $\mathrm{F}$ even compared with the innovator product. On the other hand, brand $\mathrm{E}$ exhibited the relatively slow average disintegration time (13.83 minutes) compared with the other.

\section{Weight variation}

The weight variation of metformin hydrochloride products under investigation was also determined (Table 3). It is a method utilized to assess uniformity of the dosage unit. As per the $\mathrm{USP}^{21}$, the weight variation limit for tablets having the average weight equal to or greater than $324 \mathrm{mg}$ is $\pm 5 \%$. Out of twenty samples, maximum of two tablets can deviate from this limit but all must fall within $10 \%$ tolerance limit. It was found that all the brands met the official standard. All tablet products showed less than 5\% weight deviations except for product $G$ which average weight deviation of a single tablet was found to be $5.99 \%$. But, this single tablet deviation was less than twice of the recommended limit (i.e. 10\%). From the result, it was found that all brands showed comparable weight variations with the innovator product and generally they met the official standards. Such uniform weights of brand products are an important feature of tablets' uniformity which might be a good indicator of the tablets' content uniformity. Tablets -to- tablets consistency of weight could result from running and monitoring the manufacturing process and the functioning of tablets' compression tooling in a proper way. 


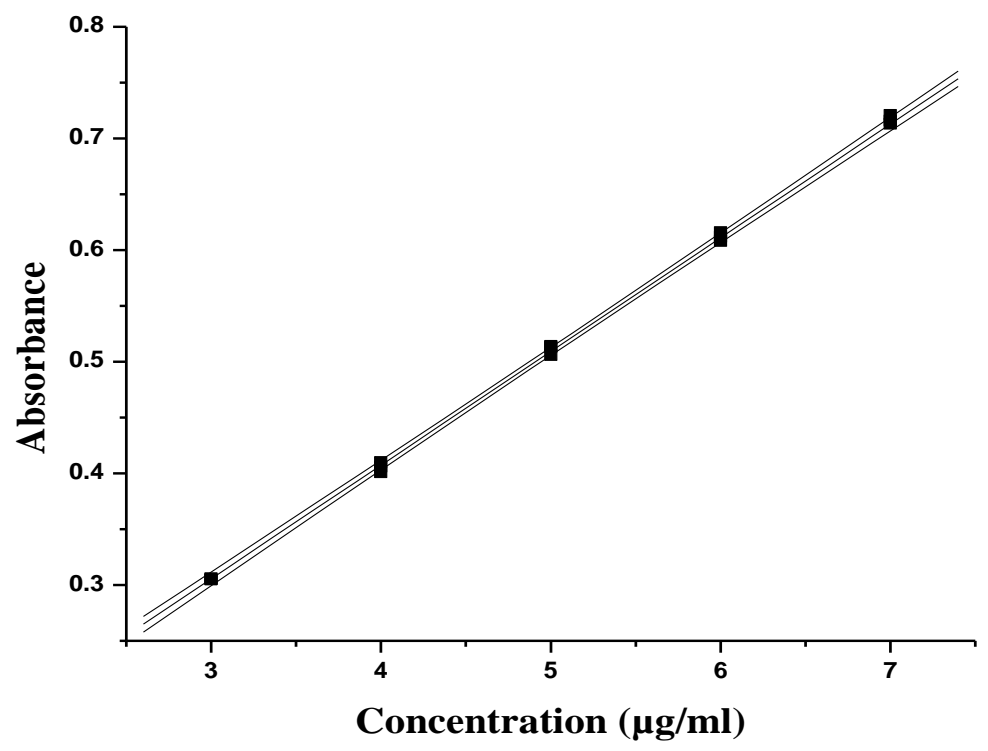

Figure 2: Metformin hydrochloride calibration curve at $\lambda$ max of $233 \mathrm{~nm}$ in phosphate buffer of $\mathrm{pH} 6.8$ with upper and lower $95 \%$ confidence limits

In vitro dissolution study from oral solid dosage forms is an important prerequisite for drug bioavailability and can be used as an alternative approach for bioequivalence studies that can predict therapeutic equivalence between reference and test products which are pharmaceutical equivalent ${ }^{25}$. Dissolution test result of tablets may indicate the impact of ingredients included in the formulation on the in vivo performance of the drug.

Since lowering of blood glucose level using metformin hydrochloride is desired within short time, rapid release of the drug from the dosage form is recommended. The in vitro dissolution profile of the products is indicated below in Figure 3. The drug release was more than $80 \%$ after 30 minutes for all brands. This release amount comply USP $^{21}$ specification stating that, for metformin hydrochloride tablets, not less than $80 \%$ of the labeled amount of drug should be released within 30 minutes.
The innovator product (brand A) showed drug release closer to $20 \%$ of labeled amount early in 5 minutes. Among the other tested products, brands D, F, and G, showed a relatively faster release (more than 20\%) of their drug contents within 5 min whereas brands B, C and E took above ten minutes to release more than $20 \%$. The rapid release of brand $\mathrm{F}$ is supported by the fast disintegration time (Table 2). At the end of 30 minutes, brands D and F provided maximum drug release of about $93 \%$ as opposed to brands $\mathrm{E}$ and $\mathrm{G}$ releasing about $82 \%$ of drug content in the specified time. The innovator product released $87 \%$ of drug amount within 30 minutes. Despite its higher hardness value $(118.1 \mathrm{~N})$ compared to the innovator product (103.8 $\mathrm{N}$ ), brand $\mathrm{F}$ exhibited higher amount of dissolved drugs within 30 minutes which might be due to the nature and quantity of excipients (e.g. disintegrants) used in formulation $\mathrm{F}$ or the manufacturing method followed. None of the studied samples demonstrated $100 \%$ release up to 45 minutes.

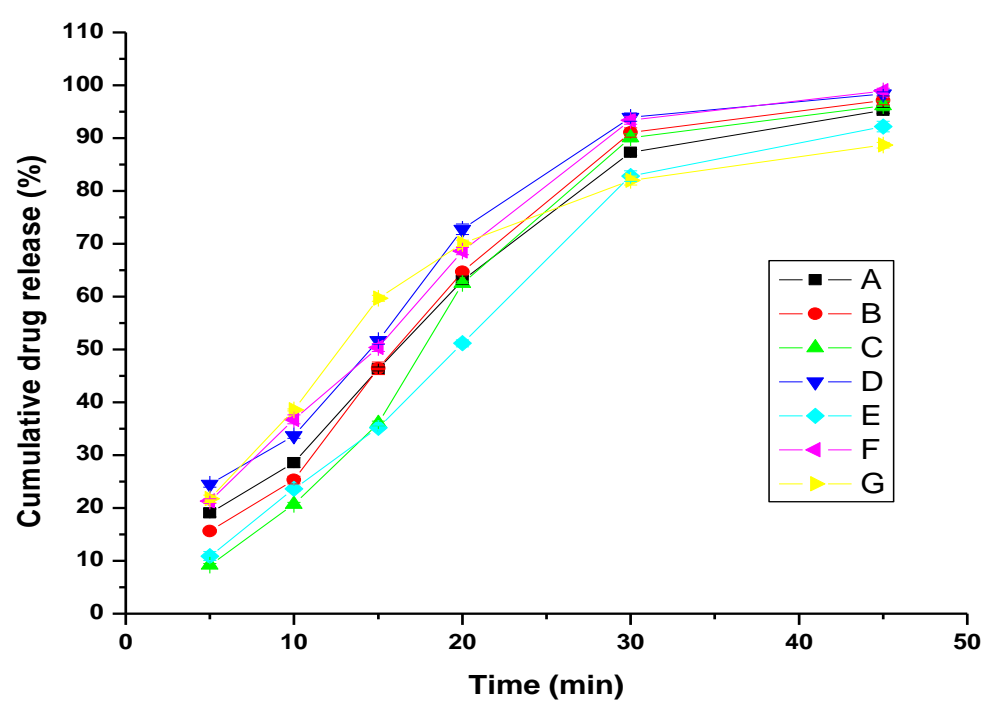

Figure 3: Cumulative in vitro release profiles of metformin hydrochloride $500 \mathrm{mg}$ tablets 


\section{Similarity factor (f2)}

To compare the dissolution profiles of the innovator and generic products, a model independent approach of similarity factor (f2) was employed. For two dissolution profiles to be considered bioequivalent or similar, similarity factor (f2) should be between 50 and $100^{26}$.

The similarity factor (f2) values of studied generic products compared to innovator (product A) are presented in Table 4. The $\mathrm{f} 2$ values for generic products were found to be in the range of 53 to 75 . Thus all brands can be considered to be equivalent to the innovator product (product $\mathrm{A}$ ) as their $\mathrm{f} 2$ values were more than 50 . Among all generic products, brand $\mathrm{B}$ showed a higher value of $\mathrm{f} 2$ (75) suggesting a more potential substitute for the innovator product than other products because as the f 2 value is becoming higher and nearest to 100 , the more will be the similarity of tested generic product with the comparator with respect to dissolution profile.

Table 4: Similarity factors (f2) for dissolution profiles of tested products

\begin{tabular}{|c|c|c|c|c|c|c|}
\hline \multirow{2}{*}{ Parameter } & \multicolumn{6}{|c|}{ Brands } \\
\cline { 2 - 7 } & $\mathbf{B}$ & $\mathbf{C}$ & $\mathbf{D}$ & $\mathbf{E}$ & $\mathbf{F}$ & $\mathbf{G}$ \\
\hline f2 value & 75 & 56 & 57 & 53 & 62 & 53 \\
\hline
\end{tabular}

\section{Assay of metformin hydrochloride tablet}

Setting concentration of active pharmaceutical ingredient in each batch of medicament to their label claim is important to quantitatively measure the amount in a tablet which is related to their functional activity ${ }^{27}$.
As depicted from Table 5, the active pharmaceutical ingredients for all metformin hydrochloride tablet brands were within specifications and satisfied the assay requirement. $\mathrm{USP}^{21}$ limits $100 \pm 5 \%$ of labeled claim for metformin hydrochloride $500 \mathrm{mg}$ tablets and the assay result for the samples varied between 95.60 and $104.37 \%$. Brand $\mathrm{E}$ had the maximum content and brand $\mathrm{C}$ contained the minimum amount of the claimed label.

Table 5: Percentage Assay of different brands of metformin hydrochloride tablets

\begin{tabular}{|l|l|l|l|l|l|l|l|}
\hline \multirow{2}{*}{ Parameter } & \multicolumn{6}{|c|}{ Brands } \\
\cline { 2 - 7 } & A & B & C & D & E & F \\
\hline Assay (\% \pm SD) & $103.17 \pm 1.11$ & $104.20 \pm 0.80$ & $95.60 \pm 1.10$ & $103.37 \pm 1.01$ & $104.37 \pm 1.10$ & $99.50 \pm 1.01$ & $\begin{array}{l}104.27 \\
0.50\end{array}$ \\
& & & & & & \\
\end{tabular}

\section{CONCLUSION}

The weight variation results for all metformin hydrochloride tablet brands were satisfactory and found to be within $\pm 5 \%$. Even though the crushing strengths of studied products were above $100 \mathrm{~N}$, they showed complete disintegration within 15 minutes.

With respect to the $\mathrm{USP}^{21}$ dissolution monograph, all investigated products passed the test by showing more than $80 \%$ drug release in 30 minutes. Furthermore, the dissolution profile of generic products exhibited similarity with respect to the comparator product since $f 2$ values are more than $50 \%$ for all and generally the results of generic products suggested comparable physicochemical quality to the innovator product.

From this study, it has been revealed that all investigated brands of metformin hydrochloride tablets available in Addis Ababa market fulfilled the pharmacopoeial requirements and may be used interchangeably.

\section{ACKNOWLEDGEMENTS}

The authors are grateful to Addis Ababa University for providing laboratory access to conduct the study. The authors are also thankful to the EFDA for donating metformin hydrochloride reference material.

\section{CONFLICTS OF INTEREST}

The authors report no conflicts of interest in this work

\section{REFERENCES}

1. Boruah P, Chakraborty J, Dash S. A comparative evaluation of antidiabetic potentiality found in different marketed polyherbal formulation using glucocorticoid-induced hyperglycaemia in rabbit. Int $\mathrm{J}$ Curr Pharm Res. 2017; 9:83-85.

2.Prithi IJ, Chowdhury SF, Chowdhury ST. Comparative in vitro dissolution test and other physicochemical parameters of some commercially available metformin $\mathrm{HCl}$ brands in Bangladesh. Pharma Innov. 2018; 7:5-8.

3. Ramalingam P, Reddy YP, Kumar KV, Chandu BR, Rajendran K. Evaluation of metformin hydrochloride in Wistar rats by FTIR-ATR spectroscopy: A convenient tool in the clinical study of diabetes. J Nat Sc Biol Med. 2014; 5:288-292.

4. Sachan AK, Kumar V, Gupta A. Comparative in-vitro evaluation of four different brands of metformin $\mathrm{HCl}$ available in Kanpur district, India. Pharm Lett. 2016; 8:419-424.

5. Garza-Ocanas L, Gonzalez-Canudas J, Tamez-dela OE, Badillo-Castan C, Gomez-Meza MV, Romero-Antonio Y, Molina-Perez A, AmadorHernandez AG. Comparative Bioavailability of Metformin Hydrochloride Oral Solution Versus Metformin Hydrochloride Tablets in Fasting Mexican Healthy Volunteers. Adv Ther. 2018; 36:407-415.

6. Mokhtare B, Cetin M, Ozakar RS, Bayrakceken H. In vitro and in vivo evaluation of alginate and alginate-chitosan beads containing metformin hydrochloride. Trop J Pharm Res. 2017; 16:287-296.

7. World Health Organization. Proposal to waive in vivo bioequivalence requirements for WHO Model List of Essential Medicines immediaterelease, solid oral dosage forms. Technical Report Series, No 937, 2006, Annex 8.

8. Osman Z, Osman AE, Abedelghayoum AM. Comparative evaluation of physicochemical properties of some commercially available brands of metformin $\mathrm{HCl}$ tablets marketed in Sudan. IAJPR. 2017;7:7471-7477.

9. Hanafy AF. In-vitro bioequivalence, physicochemical and economic benefits study for marketed innovator and generic ciprofloxacin hydrochloride tablets in Saudi Arabia. J Appl Pharm Sci. 2016;6:63-68.

10. Tacca MD, Pasqualetti G, Paolo AD, Virdis A, Massimetti G, Gori G, Versari D, Taddei S, Blandizzi C. Lack of pharmacokinetic 
bioequivalence between generic and branded amoxicillin formulations. A post-marketing clinical study on healthy volunteers. $\mathrm{Br} \mathrm{J} \mathrm{Clin}$ Pharmacol. 2009; 68:34-42.

11. Alghannam AFA, Aslanpour Z, Evans S, Schifano S. A systematic review of counterfeit and substandard medicines in field quality surveys. Integr Pharm Res Pract. 2014; 3:71-88.

12. Adegbolagun OA, Olalade OA, Osumah SE. Comparative evaluation of the biopharmaceutical and chemical equivalence of some commercially available brands of ciprofloxacin hydrochloride tablets. Trop J Pharm Res. 2007; 6:737-745.

13. Eraga SO, Arhewoh MI, Oruh EP, Iwuagwu MA. A comparative evaluation of the pharmaceutical quality of different brands of metformin hydrochloride tablets available in Abuja, Nigeria. WAJP. 2017; 28:61-71.

14. Afifi SA and Ahmadeen S. A Comparative Study for Evaluation of Different Brands of Metformin Hydrochloride $500 \mathrm{Mg}$ Tablets Marketed in Saudi Arabia. Life Sci J. 2012; 9:4260-4266.

15. Olusola AM, Adekoya AI, Olanrewaju OJ. Comparative Evaluation of Physicochemical Properties of Some Commercially Available Brands of Metformin $\mathrm{HCl}$ Tablets in Lagos, Nigeria. J Appl Pharm Sci. 2012; 2:41-44.

16. Sougi A, Ofori-Kwakye K, Kuntworbe N, Kipo SL, Boakye-Gyas ME. Evaluation of the Physicochemical and in vitro Dissolution Properties of Metformin Hydrochloride Tablet Brands Marketed in Five Cities in Ghana. Br J Pharm Res. 2016; 9:1-14.

17. Zakeri-Milani P, Nayyeri-Maleki P, Ghanbarzadeh S, Nemati M, Valizadeh H. In-vitro bioequivalence study of 8 brands of metformin tablets in Iran market. J Appl Pharm Sci. 2012; 2:194-197.

18. World Health Organization. Global surveillance and monitoring system for substandard and falsified medical products [internet]. [Cited 2019
November 21]. Available from: https://www.who.int > medicines , regulation > ssffc > surveillance.

19. Krishnaiah YSR, Yang Y, Bykadi S, Sayeed VA, Khan MA. Comparative evaluation of in vitro efficacy of colesevelam hydrochloride tablets. Drug Dev Ind Pharm. 2014; 40:1173-1179.

20. Wong SS, Ngo SNT. Use of In vitro Dissolution Testing to Assess Multiple Generic Metformin Tablets. J Pharm Res Int. 2018; 21:1-9.

21. United States Pharmacopoeia/National Formulary (USP36/NF31). The United States Pharmacopoeial Convention. Rockville, MD, USA; 2013.

22. Getachew A, Desta W, Bekele A. Comparison of Enset Starch with Other Widely Known Commercial Starches and Its Significant Applications in Pharmaceuticals. Br Biotechnol J. 2016; 14:1-8.

23. Hettiarachchi TW, Wickramaratne DBM, Sudeshika SHT, Niyangoda D, Sakeena MHF, Herath HMDR. Comparative in-vitro evaluation of metformin $\mathrm{HCl}$ and paracetamol tablets commercially available in Kandy district, Sri Lanka. Int J Pharm Pharm Sci. 2015; 7:520-524.

24. Gupta MM, Gupta M. In-vitro Pharmaceutical Quality Control Testing: a Comparative study of Different Brands of Metformin Tablets Available in the Trinidad \& Tobago, West Indies. J. Pharm. Sci. \& Res. 2016; 8:238-243.

25. Guidelines for Bioavailability \& Bioequivalence Studies, Central Drugs Standard Control Organization (CDSCO), Directorate General of Health Services, Ministry of Health \& Family Welfare, Government of India, New Delhi [internet]. [Cited 2019 November 15]. Available from: https://cdscoonline.gov.in > CDSCO.

26. Guidance for Industry. Dissolution Testing of Immediate Release Solid Oral Dosage Forms [internet]. [Cited 2019 November 16]. Available from: https://www.fda.gov > media > download.

27. Thakuri GMS, Yadav KK, Chhetri RR. Comparative in-vitro analysis of different brands of paracetamol tablets available in Nepal. JCLM. 2016; 4:645-648. 